\title{
The Grassroot Glory of Jamaica's Athletics: Analyzing the Perceived Impact of the COVID-19 Pandemic on High School Student-Athletes' 2021 Athletic Championship
}

Van Der Rowe ${ }^{1}$

Faculty of Science and Sport, University of Technology

\section{Laurence Garriques}

Faculty of Science and Sport, University of Technology https://orcid.org/0000-0001-5658-8139

https://orcid.org/0000-0002-6592-7793
Received: August 4, 2021

Online Published: September 30, 2021

DOl: 10.30655/besad.2021.36
Accepted: September 15, 2021

https://doi.org/10.30655/besad.2021.36

\begin{abstract}
The purpose of this study was to analyze the perceived impact of the COVID-19 pandemic on high school track and field athletes' 2021 championship experience from the coaches' perspective. A quantitative approach which utilized a descriptive survey design was used to collect and analyze data. A combined sampling method that included snowball and purposive sampling techniques were used to survey 43 of the 71 track and field head coaches that took part in the ISSA Boys and Girls Athletic Championship 2021. The results of the study indicated that the COVID-19 pandemic significantly impacted many student-athletes preparation and participation in Champs 2021. The effects of the pandemic also affected the students' physical and psychological abilities to effectively participate in Champs 2021. This required many of the coaches to employ coping mechanisms to combat the effects of the COVID-19 pandemic. With Jamaica being a powerhouse in track and field, through the development of grassroot programs like the ISSA Boys and Girls Athletics Championship. The impact of the pandemic on these feeder programs will directly impact the development of new talent and gold medal winning performances for future national teams.
\end{abstract}

Keywords: Pandemic, coach, perception, new normal

${ }^{1}$ Corresponding Author: Van Der Rowe vanderroweg@gmail.com

Faculty of Science and Sport, University of Technology, Jamaica Kingston, Jamaica, W.I. 


\section{Introduction}

The rich history of high school track and field in Jamaica predates the establishment of the Ministry of Culture, Gender, Entertainment and Sport (MCGES), which is the portfolio Ministry with responsibility for sports in Jamaica. Schools were well engaged in inter-school competitions before the MCGES' establishment, formerly known as the Ministry of Sports in its onset (Patterson, 2016). High school sports were being played by many Jamaicans who attended traditional and non-traditional schools. The formation of the Inter-Secondary Schools Sports Association (ISSA) in 1910, long before Jamaica competed in its first Olympic Games, which further emphasized the importance of high school sports in Jamaica. However, the primary sport at the high school level was track and field (Brown, 2021; Patterson, 2016). The Boys' and Girls' Championship (Champs) is the name of the legendary high school track and field championship in Jamaica and the only one of its kind in the world (Brown, 2021). The Wolmer's Boys maroon and gold team won the first year of the championship in 1910. While in Brown's Town, St Hilda's High School won the inaugural girls' championship (Brown, 2021; Patterson, 2016).

High school sports in Jamaica have a rich history and culture of rivalry, excitement, and patriotism, which sees a continuous battle to win championships in several sports (Brown, 2021). Some schools have tried a variety of methods to secure victory and bragging rights, including transferring students, strengthening athletic facilities, and investing millions of dollars in sports (Patterson, 2016). Thousands of Jamaican high school students have benefited and made a career from their abilities both here and abroad, demonstrating the importance of sports in the lives of students and its contribution to national development (Brown, 2021; Patterson, 2016). Track and field is one of the most anticipated high school sporting events on the sporting calendar in Jamaica, which sees people traveling from abroad to watch, recruit and support their former high school. This competitive nature of high school track and field in Jamaica and the talent level of our students have created revenues, scholarships and opportunities for students, coaches and the ordinary Jamaican who can earn from Champs (Brown, 2021). Schools that perform well at Champs are also awarded financial support from ISSA, development, and promotional opportunities from sponsors. Schools also sell themselves to prospective students with sports as part of the rich culture that students will be engaged in when they enroll in the school. On the other hand, ISSA earns millions of dollars from Champs yearly, which helps to cover the running of the event, subsidizing other sporting areas and running the organization's daily expenses (Bogle, 2016; Brown, 2021).

Despite the positive impact of high school track and field on student-athletes, schools, supporters, recruiters, and ISSA, Champs 2020 was canceled because of the global COVID-19 pandemic. In addition, the cancellation saw millions of dollars in losses being suffered by ISSA and schools that were in full preparation mode for Champs 2020. The student-athletes also suffered losses in scholarship opportunities and some final year students missed their final opportunity to participate in Champs. In 2020, sports in Jamaica and the rest of the world came to a standstill because of a worldwide outbreak of the COVID-19 virus that forced governments to implement very strict measures on gatherings and the wearing of masks. This meant that there was no hope for Champs 2020, as the world grappled with this new pandemic and the uncertainty of transmission, effects, and treatment of the virus (Graham, 2021; Mansingh, 2021; UN, 2020).

Like Champs, many sports and sporting organizations around the world suffered a similar fate. According to Grix et al. (2021) the unprecedented COVID-19 pandemic, as well as the lockdowns enacted to stop it, has had a significant impact on both professional and grassroots sport. Due to a lack of live viewers, elite sport teams and organizations have faced immediate financial losses. Grix et al. (2021) further explained that it is now obvious how the pandemic's influence on sport and society varies depending on a country's political leadership and philosophy, as well as its "exit" strategy. Many of the world's political leaders, who looked impregnable before the pandemic, have had their vulnerabilities 
exposed (Grix et al., 2021). The UN (2020) also indicated that most major sporting events at the international, regional, and national levels have been canceled or postponed to protect the health of athletes and others involved - from marathons to football tournaments, athletics championships to basketball games, handball to ice hockey, rugby, cricket, sailing, skiing, weightlifting to wrestling, and more were all canceled or postponed. The Olympics and Paralympics have been postponed for the first time in modern history and took place in 2021. The UN (2020) further explained that the worldwide sporting sector is estimated to be worth $\$ 756$ billion each year. Millions of jobs are at stake as a result of the COVID-19 pandemic, not only for sports professionals but also for those in allied retail and athletic service businesses linked to leagues and events, such as travel, tourism, infrastructure, transportation, catering, and media broadcasting, among others.

Seeing the cancellation of Champs that occurred in 2020, many coaches, athletes, and schools were optimistic that the preparation for the 2021 season would have started in the summer of 2020 . However, only the well-equipped schools, with facilities and other resources, were able to have training sessions from time to time. Despite that, the restrictions by the government changed quite often in response to the rapid spread of the COVID-19 virus and still posed a challenge for those schools. These unpredictable changes restricted gathering numbers, introduced curfew hours, and allowed movement only for essential workers. All of these measures affected the mental and physical preparation of athletes for Champs 2021. The schools that had the resources created a COVID-19 bubble, intended to keep students together during the preparation period. Schools that had limited resources had no choice but to have students travel to school on specific days for training. Some coaches even became creative and held training sessions online.

The Government of Jamaica had very strict COVID-19 restrictions in place during the preparation and execution of Champs 2021. These restrictions included specific requirements for sports participation in the granting of permission for high school athletes to return to play. As a result, the beginning of the 2021 high school track and field season was full of much uncertainty as permission was needed for the staging of any sporting activity. Permission was granted by the Government of Jamaica for qualifying meets to be held but the decision was later rescinded because of spikes in the COVID-19 transmission on the island. The uncertainty and the disruptions in training programs certainly affected the mental readiness and physical preparation of many student-athletes heading into qualifying meets. Many of the scheduled meets were either canceled or postponed as soon as a new date was set. This also affected the staging of Champs 2021 with the dates being changed twice because of the spike in the transmission levels island-wide and the government's restrictions.

A few qualifying meets were held, however, the structure of Champs 2021 changed to facilitate the COVID-19 pandemic and government restrictions. Despite the changes, there was a national call by the Jamaica Parent Teachers' Association for the Boys' and Girls' Championship to be canceled, out of the fear that parents had regarding their children contracting the virus and taking it home to elderly relatives (The Gleaner, 2021). As a result of the mounting levels of uncertainty, pressure, and parental concerns for the safety of their children, many parents and guardians did not allow their children to take part in school training sessions; thus, some student-athletes missed the opportunity to qualify for Champs 2021. Furthermore, the schools with inadequate resources and low student participation withdrew from Champs 2021. The championship was eventually held with a small complement of schools between May 11-15, 2021, instead of its traditional March dates. The ISSA Boys and Girls Athletic Championship that is held annually facilitates secondary schools from all parishes, areas, gender, and high school-related age groups in Jamaica. The annual event usually has the participation of over 150 schools at each championship. The 2021 season only had 71 schools participating, 676 boys and 638 girls, with representation coming from schools in 13 parishes of Jamaica. Additionally, over 100 coaches represented the 71 schools that participated in Champs 2021. Champs was also held without its 
traditional spectator support, instead, it was streamed live on television and the internet.

The scaled-down proceedings of Champs 2021 took away the culture, finance, and spectacular athletic performances that we have grown to love about the championship. As a result, this research sought to analyze the perceived impact of the COVID-19 pandemic on the high school student-athletes' 2021 championship experience from the coaches' perspective. This study has provided a better understanding from the coaches' perspective of the challenges encountered in preparing athletes for Champs 2021. The study also explains the perceived mental impact on student-athletes, the coping mechanisms employed by coaches, and the impact of the pandemic on the students' athletic performance. This study can significantly contribute to the body of knowledge surrounding the impact of the COVID-19 pandemic on sports in Jamaica, making specific reference to grassroot development. ISSA, high schools, the government, and other stakeholders can use the results of this study to better plan for further eventualities such as the COVID-19 pandemic.

\section{Method}

The methods chosen for this research sought to get a unique view of how the student-athletes were impacted by the COVID-19 pandemic. With the COVID-19 restrictions still being enforced by the Government of Jamaica, it was difficult to reach student-athletes. Furthermore, some of the athletes have completed their schooling and are overseas or otherwise unreachable by their school. The coaches' perspective could comprehensively reflect the challenges, coping mechanisms, the perceived mental impact, and student-athletes overall athletic performance for the 2021 season when compared to other seasons. As a result, a quantitative descriptive survey method was employed targeting the coaches that participated in the 2021 ISSA Boys and Girls Athletic Championship.

\section{Research Approach and Design}

The research took the form of a quantitative approach in gathering, analyzing, and presenting the results of the study. This approach was chosen because it suited the type of data that was collected and the procedure for the collection of data. Quantitative research is the systematic, empirical investigation of a phenomenon via statistical, mathematical, or computational techniques (Zyphur \& Pierides, 2017). The quantitative approach was used to answer questions about the relationships among measured variables to observe and measure the impact of the pandemic on student-athletes. Furthermore, the research utilized a descriptive survey design geared towards reaching the majority of the coaches that participated in the 2021 ISSA Boys and Girls Championship. The descriptive design allows the researcher to gather, analyze, classify, and tabulate the data around the conditions, frequency of training, training strategies, support system, coping mechanisms, physical and the perceived psychological impact on student-athletes. The survey used a structured questionnaire that was administered online via Google Forms.

\section{Population and Sample}

The population for this study comprised of high school track and field coaches that took part in the 2021 ISSA Boys and Girls Athletic Championship between May 11-15, 2021. A total of 71 schools from traditional, non-traditional, urban, and rural areas across Jamaica took part in Champs 2021. The invitation to participate in the research was sent to all 71 head coaches that took part in the championship. However, only 43 coaches took up the invitation to participate in the study, all 43 coaches filled out their questionnaires and submitted using Google Forms. Majority of the coaches (39.5\%) represented the $31-40$ age group, while another $37.2 \%$ represented the $41-50$ age group. Other age 
groups that participated include the 20-30 age group (16.3\%), 61-70 age group (4.7\%), and 51-60 age group (2.3\%). As it relates to the gender of the coaches, $83.7 \%$ were males and $16.3 \%$ were females.

Furthermore, $69.8 \%$ of the participating coaches worked at schools that are in rural areas, while $27.9 \%$ of the coaches worked at schools located in urban areas and another 2.3\% were in suburban areas. As it relates to the parishes, the highest representation came from the capital Kingston, with 16.3\%; however, the participation from the other parishes was evenly distributed, with only one parish not being represented. The requirement to coach high school track and field in Jamaica is a level one or two certificates in coaching track and field from the Jamaica Athletics Administrative Association (JAAA) or any other qualifying body, some coaches are allowed to coach with a degree in physical education (partially accepted).

For this study, each school was only allowed one representative in the form of their head coach for their track team; despite each school having multiple coaches with different responsibilities, the researchers believed that the head coach was the most appropriate person to provide a comprehensive analysis and reflection on their student-athletes. The study sample represents a margin of error of $5 \%$, a confidence level of $95 \%$, and a confidence interval of 9.45 . The sampling methods that were utilized in this research were the purposive and snowball sampling methods. In the purposive sampling method, the researchers selected participants with specific knowledge and characteristics needed for this study. While in the snowball sampling method, participants made referrals for the recruitment of samples for the research project.

\section{Data Collection Procedure}

The research was conducted while complying with all ethical standards that govern research and the guidelines established by the researchers' university. A research proposal was first submitted to the University's Ethics Committee for ethical clearance (2021/07/FOSS/112). Once ethical clearance was granted, the researchers proceeded to write a letter to ISSA seeking their permission for the research to be conducted with their coaches. ISSA is comprised of all high school principals whose school has participated in Champs over the years. ISSA's president evaluated our request for the research and granted permission for us to conduct the research with their coaches. Once permission was granted, the researchers then sent letters to the 71 head coaches seeking their permission to participate in the study. The researchers then created a Google Form questionnaire with 20 structured multiple-choice items that were distributed to the 43 coaches that agreed to participate.

With the poor internet connectivity in some parts of Jamaica, the coaches were given up to two weeks for the completion and submission of the questionnaire. The estimated completion time of the questionnaire was 7 minutes, however, the average completion time recorded for the coaches was 15 minutes. At the onset of the data collection procedures, a letter was sent to participants through ISSA's office informing them about the procedures and purpose of the research. To ensure the validity of the research instrument, the researchers created the format and content of the questionnaire from similar research that was conducted on the impact of the COVID-19 pandemic on sports and student-athletes. To ensure that no personal identifying information was obtained from the coaches and the process remained anonymous, the researchers dialogued with ISSA to get the questionnaire sent to their track and field coaches via a WhatsApp group, emails, and other means of communication used by the organization. To ensure that participants understood what was required of them, the first page of the Google Form explained the purpose of the research and other relevant information while highlighting that they are giving consent to participate by proceeding to the questions. If participants had questions or concerns, they were able to relay them through ISSA's office using their WhatsApp group or email 
addresses and the messages were able to research the researchers for feedback to be provided using similar channels.

\section{Data Collection Tools}

A structured questionnaire was created using Google Forms, aimed at getting the coaches' perspective of their students' overall performance in the ISSA Boys and Girls Athletic Championship 2021. The questionnaire contained 20 structured questions with multiple choices. From the 20 questions, four were geared towards collecting demographic information and the other 16 questions were directly linked to the impact of the pandemic on student-athletes' 2021 championship experience. The questions all had pre-set responses for participants to choose from, however, each question gave participants the option to add their own responses if they were different from the pre-set ones. Some of the questions in the questionnaire sought responses in regards to the perceived physical and psychological effects of the pandemic on student-athletes, the coping mechanisms that were employed throughout the period, the impact of the pandemic on student-athletes preparation and qualifying meets for the championship, analyzing the overall performance of their student-athletes in comparison to other years of the championship, the types of preparation made to accommodate student-athletes during the pandemic and highlighting areas of recommendations or changes that could have been made to improve the student-athletes performance and the overall championship experience.

\section{Data Analysis}

The data from the questionnaire were tabulated using IBM SPSS statistics 22 and the analysis of the data was done using descriptive statistics. The data was downloaded from Google Forms to a Microsoft excel document where the necessary preparation was made for export to the analyzing software. SPSS is the statistical tool that was used to analyze the data to provide summaries and relationships between variables. The specific areas of descriptive statistics that were analyzed included using crosstab commands to summarize the coaching age of the coaches. A crosstab was also done to examine the significance between the perceived mental impact and the types of coping mechanisms that were used. After the data was analyzed in SPSS the results were reported using figures and summaries. An interpretation and description of the results were done based on descriptive statistics standards.

\section{Ethical Considerations}

Ethics is a very important aspect of research, as a result, the safety and privacy of participants must be handled with due care. This research followed all ethical standards that have been established in research and as indicated by the University's Ethics Committee. Issues that normally occur during research such as this include consent to participate and privacy of individuals and institutions. The researchers took all the necessary steps to ensure that the participants gave their consent to participate (the survey sought consent before participants could proceed to the questions) and ensured that no identifying information either directly at individuals or institutions were required or collected. All responses were anonymous, and the researchers ensured that the data collected was encrypted and is now stored on password-protected devices. The data from the research will be kept for up to five years before being deleted or destroyed. 


\section{Findings}

The research targeted coaches to provide a comprehensive summary and analysis of the impact of the COVID-19 pandemic on the performance of their student-athletes in Champs 2021. A total of 43 coaches responded to the questionnaire which represented 43 high schools that took part in the 2021 season. The results are presented in a descriptive format using subheadings from the questionnaire.

\section{Student's Athletic Performance}

The coaches were asked to indicate the types of preparation that were made to facilitate the resumption of training for student-athletes. Majority of the respondents (48.8\%) indicated that students traveled from home for training each day, but COVID-19 protocols were observed. Another $23.3 \%$ of the respondents indicated that their training schedules were modified to accommodate smaller groups on specific days and times. Another $20.9 \%$ of the respondents indicated that they created a training bubble where the student-athletes would stay in camp (dorm) during the preparation and competition periods for Champs 2021. Furthermore, another 7\% of the respondents indicated that the students trained virtually. On average, track and field student-athletes in Jamaica and other parts of the world normally train 5 days per week (Pashley, 2014). With this narrative, the respondents were asked about the frequency of training during the COVID-19 pandemic. Majority of the respondents (62.8\%) indicated that they trained 3-4 days per week. Another $23.3 \%$ of the respondents indicated that they train 5-6 days per week, while another 9.3\% indicated that training was held 1-2 days per week. The other responses included training once per week (2.3\%) and training once per day (2.3\%).

\section{The most significant challenges}

When asked about the most significant challenges in preparing student-athletes for the 2021 Champs season in a pandemic, the participants (53.5\%) indicated that the uncertainty of Champs 2021 caused much anxiety. While $16.3 \%$ of the respondents indicated that the poor turnout of student-athletes in the preparation phase was the most significant challenge faced. Other responses included limited time for preparation (11.6\%), limited resources (7\%), fear of contracting the virus (7\%), and injuries (4.7\%).

\section{Student-athletes' performance}

When asked about the impact of the pandemic on athletic performance, $88.4 \%$ of the respondents believed that when compared to other years of the championship, the pandemic-related challenges significantly affected their students' performances. Specifically, 37.2\% of the respondents indicated that their students' performance was average, while $27.9 \%$ indicated that when compared to other championship years, their students' performance had declined. Other responses indicated that performance was below average (14.3\%), excellent (11.3\%), poor (4.7\%), and $4.7 \%$ also indicated that their students' performance did not change. Participants were asked about what contributed to the poor performance of their students, the consensus by $41.9 \%$ of the respondents indicated that a lack of preparation contributed to the poor performance. Another $23.3 \%$ of the respondents indicated that they were satisfied with the level of performance of their student-athletes. Other significant reasons that were given included' COVID-19 restrictions (14\%) and poor support from schools and parents (11.6\%). The results further indicated that $51.9 \%$ of the coaches that held training sessions 3-4 days per week had average overall performances of student-athletes at Champs 2021. While 60\% of the coaches that had training sessions 5-6 days per week indicated that their students' overall performance for Champs 2021 was excellent. Additionally, $50 \%$ of the coaches that had training sessions $1-2$ days per week indicated a decline in the overall performance of their student-athletes, while the other $50 \%$ of the coaches that 
had training sessions 1-2 days per week indicated that their student-athletes overall performance was poor.

\section{Preparation and poor performance}

An analysis was done using the types of preparation that were made to facilitate training sessions during the pandemic and students' performance. This was used as the indication of what contributed to the poor performance of the athletes or the team. Furthermore, $47.6 \%$ of the coaches that had students traveling from home each day for training indicated that lack of preparation contributed to their poor performance. Additionally, $44.4 \%$ of the participants that were in training camps (bubbles) indicated that they were satisfied with their student-athletes performance level, however, 33.3\% of the participants that indicated training sessions were done virtually, blamed the COVID-19 restrictions for their poor performance. Another $30 \%$ of the participants that had training in small groups on specific days and times also blamed the COVID-19 restrictions and lack of preparation (50\%) for their poor performance.

\section{The Noticeable Physical and Psychological Effects}

The coaches were asked to indicate the most noticeable physical effects of the pandemic on their student-athletes. Majority of the respondents (55.8\%) indicated that they noticed their student-athletes had gained weight. The other responses included poor athletic performance (16.3\%), a decline in the technical skills of the student-athletes (11.6\%), drop in fitness levels (11.6\%), delayed onset muscle soreness $(2.3 \%)$ and $2.3 \%$ of the respondents indicated that there were no physical effects of the pandemic on their student-athletes. The participants were also asked about the perceived psychological effect of the COVID-19 pandemic on their student-athletes. Majority of the respondents (58.1\%) indicated that their athletes had a lack of motivation and interest to participate in training, pre-qualifying meets, and Champs 2021. Other responses related to the perceived physiological effect of the pandemic included mood swings (14\%), anxiety (9.3\%), expressed feelings of stress ( $7 \%$ ), feelings of depression $(4.7 \%)$, and another $7 \%$ indicated that there were no perceived psychological effects of the pandemic on their student-athletes.

\section{Coping Mechanisms}

Participants were asked about the need for coping mechanisms during the preparation and participation of Champs 2021. Majority (88.4\%) of the coaches indicated that their student-athletes required coping mechanisms during the COVID-19 pandemic. When asked about the types of coping mechanisms used, $79.1 \%$ of the respondents indicated that they used motivational talks to help students cope with the effects of the pandemic. Other coping mechanisms used included reassurance (9.3\%), school/teacher support (4.7\%), counseling (2.3\%), and $4.7 \%$ indicated that no coping mechanisms were needed. As it relates to the effectiveness of the mechanisms used, the majority of the respondents (76.7) believed they were somewhat effective. Another $18.6 \%$ of the respondents believed the coping mechanisms were very effective. Additionally, the results of the analysis further indicated that motivational talks were used for a lack of motivation and interest (88\%) which was the most observed psychological effect by the coaches.

\section{The Champs Experience in a Pandemic}

The major challenge expressed by the coaches during the 2021 championship was reassuring and motivating athletes $(60.5 \%)$, while $16.3 \%$ of the participants believed that the changes in the championship schedules created the most challenges. Despite the challenges faced in the 2021 season, the coaches believed that better support from the government (46.3\%), better support from schools and 
parents (30.2\%), and more time for preparation were all needed to improve the 2021 championship. The coaches believed that the challenges faced in 2021 may have affected student-athletes' chances of getting overseas scholarships (44.2\%), financial support (39.5\%), and getting local scholarships (2.3\%), while $14 \%$ of the respondents did not believe the pandemic affected the chances of their student-athletes. Based on the challenges, the level of organization, and the performance of student-athletes, the coaches rated the overall experience of Champs 2021 when compared to other years as $70 \%$ effective.

\section{Discussion}

This section is being presented using the research questions from the survey to explain, clarify, and scrutinize the study's findings to those of other studies. However, there have been relatively few studies done on the impact of the pandemic on high school student-athletes in track and field. The purpose of this study was to analyze the perceived impact of the COVID-19 pandemic on high school track and field athletes' 2021 championship experience from the coaches' perspective.

\section{To what extent was the students' athletic performance impacted by the pandemic?}

The results of this study indicated that $88.4 \%$ of the coaches believed that the COVID-19 pandemic had some form of impact on the students' athletic performance. One of the most crucial impacts of the pandemic was on the student-athletes' ability to adequately prepare for Champs 2021. The government restrictions and the fear of contracting the virus meant that coaches lost crucial preparation periods. Liu's (2021) study also found that the COVID-19 pandemic has impacted student-athletes' athletic performance in their study.

Majority of coaches in this study indicated that they had no choice but to have students travel from home each day for training and in some cases, on specific days and times. This would have reduced the 5-6 days that track and field athletes normally train, most of the coaches conducted training sessions 3-4 days per week; however, the coaches that had the facilities and other resources to create a bubble had more frequent training days. Shepherd et al. (2021) study also found that prior to the COVID-19 pandemic, student-athletes had access to a wide range of resources, including equipment, staff, and knowledge of training programs, which helped them engage more in physical activity.

The COVID-19 restricted access to resources, affecting student-athletes participation in pre-pandemic physical exercise and sport-specific training. The results of this study also indicated that coaches that facilitated training 3-4 days per week or less had average to poor performances from student-athletes. Liu's (2021) study has corroborated this result indicating that $77.4 \%$ of athletes in their study currently train for fewer than 8 hours each week. The athletes' ability to sustain peak fitness is influenced by the significant reduction in training time and change in setting. On the other hand, the results of this study indicated that coaches that were able to have training camps (bubble) facilitated training more frequently and indicated better student performances.

\section{What were the noticeable physical and psychological effects of the pandemic on student-athletes?}

The results of this study indicated that the majority of the coaches $(67 \%)$ observed increased weight gain and poor technical skills in most of their athletes as a result of the COVID-19 pandemic, these may have resulted from house confinement, increased consumption, and lack of training. This result was corroborated by Tayech et al. (2020) review that found the most significant physical impact of the pandemic on student-athletes was weight gain. Tayech et al. (2020) research found that during the 
confinement athletes needed to have participated in cardiovascular fitness exercises and the appropriate resistant training exercise to maintain fitness level and body weight.

On the other hand, the results of this study indicated that the most perceived psychological effects of the pandemic on student-athletes were the lack of motivation and interest to participate in track and field, this was indicated by $58.1 \%$ of the coaches. The review conducted by Tayech et al. (2020) also found that the most significant physiological effects of the pandemic on student-athletes were anxiety, lack of motivation, and depression. McGuine et al. (2021) carried out a study of 13000 adolescent student-athletes in the United States and found that anxiety and depression were the most expressed psychological impacts of the COVID-19 pandemic.

\section{What types of coping mechanisms were used with student-athletes during the COVID-19 pandemic?}

The results of this study indicated that the majority of the coaches (88.4\%) tried to tackle the psychological effects of the pandemic with coping mechanisms. The most used and required coping mechanism by coaches was motivational talk. This may have been what many of the high school coaches were trained to use or the type of support from schools and parents to provide the most effective coping mechanisms may have been missing. Szczypinska et al. (2021) study has corroborated this result by indicating that reassuring, motivating, and helping student-athletes to accept and adapt to the situation of the pandemic are the best ways for coping. Tayech et al. (2020) and McGuine et al. (2021) also believe in a support system for student-athletes struggling with anxiety and depression during the COVID-19 pandemic. Tayech et al. (2020) and McGuine et al. (2021) study asserted that school personnel and coaches play an important role in providing coping mechanisms to reassure, motivate, and help students to accept the situation and adapt.

\section{The Champs Experience in a Pandemic}

The results of this study indicated that reassuring and motivating the student-athletes to continue training and participating was the most challenging part of Champs 2021. Shepherd et al. (2021) believe that the pandemic would have significantly hampered the level of preparation and competition that student-athletes would have gotten through developmental meets and internal competitions. Despite the challenges that were faced by student-athletes and coaches in the execution of Champs 2021, majority $(46.3 \%)$ of the coaches believed that better support was needed from the government, while another $30.2 \%$ thought better support was needed from the schools and parents. The results also indicated that local and overseas scholarships and financial support were also significantly lessened by the lack of performance and the COVID-19 crisis.

\section{Conclusion}

The COVID-19 pandemic has affected the athletic performance of student-athletes in the 2021 ISSA Boys and Girls Athletic Championship based on the coaches' perception. The coaches believed that the COVID-19 restrictions, limited resources, and the lack of support from the government, schools, and parents contributed to less than average performances in some cases. Other significant challenges included reassuring and motivating student-athletes to continue training despite the uncertainty of Champs 2021. The poor turnout of athletes to training and the preparation schedules affected the amount and quality of training that student-athletes would normally receive, this ultimately affected their performance. The results also indicated that the most noticeable effects of the COVID-19 pandemic were weight gain, poor technical skills, and a lack of interest and motivation to participate in track and field. In trying to combat these effects, the coaches employed motivational talks and tried 
reassuring their student-athletes. Overall, the impact of the pandemic seems to have affected the chances of many student-athletes in getting local and overseas scholarships and financial support. Additionally, the coaches believe that the government, schools, and parents needed to have shown greater support to the student-athletes and Champs 2021. Since the pandemic does not seem to be going anywhere soon, we recommend that coaches plan a mixed modality for preparing student-athletes for the 2022 championship. We want to also suggest that schools and parents support their student-athletes by helping to create training bubbles (camps) during the qualification and competition periods which would facilitate more coach-athlete contact sessions.

Despite the results of this study, there were many limitations to consider. The study only focused on track and field which was the only high school sporting event given the green light to return to play. The participants in this study were only coaches that had students who qualified and participated in Champs 2021. Also, the research was conducted online as opposed to the traditional face-to-face process. This was a difficult process for some coaches that had challenges maneuvering the questionnaire platform. For future studies, it would be nice to get a better understanding of the impact of the pandemic on ISSA Boys and Girls Athletic Championship 2021 from the students' perspective. An investigation is also needed to fully understand the impact of the pandemic on the development of track and field and other sporting areas in Jamaica and the Caribbean.

\section{References}

Bogle, D. (2016, March 13). The cost of champs. The Jamaica Gleaner. Retrieved July 15, 2021, from https://jamaica-gleaner.com/article/sports/20160314/cost-champs

Brown, E. (2021, April 5). The progression of track and field in Jamaica, 1910- present. EDUTRAVEL. Retrieved September 11, 2021, from https://www.edbtravel.com/jamaica-track-and-field-1910-to-present/culture/\#h-jamaica-high-s chool-track-and-field

Ghanamah, R., \& Eghbaria-Ghanamah, H. (2021). Impact of COVID-19 pandemic on behavioral and emotional aspects and daily routines of Arab Israeli children. Int. J. Environ. Res. Public Health, 18(6), 1-18. https://doi.org/10.3390/ijerph18062946

Graham, R. (2021, April 25). Strict safety measures for Champs 2021, mandatory COVID test, 'bubble' among plans for event's return. Retrieved September 11, 2021, from https://jamaica-gleaner.com/article/sports/20210425/strict-safety-measures-champs-2021

Grix, J., Brannagan, M. P., Grimes, H., \& Neville, R. (2021). The impact of Covid-19 on sport. International Journal of Sport Policy and Politics,13(1), 1-12. https://doi.org/10.1080/19406940.2020.1851285

Liu, Q. I. (2021). The impact of COVID-19 pandemic on high performance secondary school student-athletes. The Sport Journal. Retrieved July 25, 2021, from https://thesportjournal.org/article/the-impact-of-covid-19-pandemic-on-high-performance-sec ondary-school-student-athletes/

Mansingh, A. (2021, February 15). Examining the resumption of sport. The Jamaica Gleaner. Retrieved July 15, 2021, from https://jamaica-gleaner.com/article/sports/20210215/examining-resumption-sport

McGuine, A. T., Biese, M. K., Petrovska, L., Hetzel, J. S., Reardon, C., Kliethermes, S. Bell, R. D., Brooks, A., \& Watson, M. A. (2021). Mental health, physical activity, and quality of life of US adolescent athletes 
during COVID-19-related school closures and sport cancellations: A study of 13000 athletes. Journal of Athletic Training, 56(1) 11-19. https://doi.org/10.4085/1062-6050-0478.20

Pashley, J. (2014, October 6). How Often We Practice. SKYD Magazine. Retrieved July 17, 2021, from https://skydmagazine.com/2014/10/often-practice/

Patterson, O. (2016). The secret of Jamaica's runners. New York: New York Times Company. Retrieved August July 17, 2021, from https://www.nytimes.com/2016/08/14/opinion/sunday/the-secret-of-jamaicas-runners.html

Pietrabissa, G., Volpi, C., Bottacchi, M., Bertuzzi, V., Usubini, G. A., Löffler-Stastka, H., Prevendar, T. Rapelli, G., Cattivelli, R., Castelnuovo, G., Molinari, E. \& Sartorio, A. (2021). The impact of social isolation during the COVID-19 pandemic on physical and mental health: The lived experience of adolescents with obesity and their caregivers. International Journal of Environmental Research and Public Health,18(6), 1-18. https://doi.org/10.3390/ijerph18063026.

Shepherd, H. A., Evans, T., Gupta, S., McDonough, M. H., Doyle-Baker, P., Belton, K. L., Karmali, S., Pawer, S., Hadly, G., Pike, I., Adams, S. A., Babul, S., Yeates, K. O., Kopala-Sibley, D. C., Schneider, K. J., Cowle, S., Fuselli, P., Emery, C. A., \& Black, A. M. (2021). The impact of COVID-19 on high school student-athlete experiences with physical activity, mental health, and social connection International Journal of Environmental Research and Public Health, 18(7), 3515. https://doi.org/10.3390/ijerph18073515

Szczypinska, M., Samełko, A., \& Guszkowska, M. (2021). Strategies for coping with stress in athletes during the COVID-19 pandemic and their predictors. Front. Psychol, 12, 1-12. https://doi.org/10.3389/fpsyg.2021.624949

Tayech, A., Mejri, A. M., Makhlouf, I., Mathlouthi, A., Behm, G. D., \& Chaouachi, A. (2020). second wave of COVID-19 global pandemic and athletes' confinement: recommendations to better manage and optimize the modified lifestyle. International Journal of Environmental Research and Public Health, 17(22), 1-12. https://doi.org/10.3390/ijerph17228385

The Gleaner. (2021, September 12). NPTAJ concerned about surge in COVID cases, calls for cancellation of $2021 \quad$ Champs. Retrieved July 30, 2021, from https://jamaica-gleaner.com/article/news/20210208/nptaj-concerned-about-surge-covid-cases -calls-cancellation-2021-Champs

The United Nations (2020, May 15). The impact of COVID-19 on sport, physical activity and well-being and its effects on social development. Retrieved July 15, 2021, from https://www.un.org/development/desa/dspd/2020/05/covid-19-sport/\#: :text=The\%2oglobal\% 20outbreak\%20of\%20COVID,activities\%20outside\%200f\%20their\%20homes.

Zyphur, M. J., \& Pierides, D. C. (2017). Is quantitative research ethical? tools for ethically practicing, evaluating, and using quantitative research: JBE. Journal of Business Ethics, 143(1), 1-16. http://dx.doi.org/10.1007/s10551-017-3549-8 